Revue bibliographique pour le domaine irano-aryen

\title{
Markham J. Geller (ed.). The Archaeology and Material Culture of the Babylonian Talmud
}

\section{Florence Jullien}

\section{(2) OpenEdition}

1 Journals

\section{Édition électronique}

URL : http://journals.openedition.org/abstractairanica/44095

DOI : 10.4000/abstractairanica.44095

ISBN : 1961-960X

ISSN : 1961-960X

Éditeur :

CNRS (UMR 7528 Mondes iraniens et indiens), Éditions de l'IFRI

Référence électronique

Florence Jullien, « Markham J. Geller (ed.). The Archaeology and Material Culture of the Babylonian Talmud », Abstracta Iranica [En ligne], Volume 37-38-39 | 2018, document 4, mis en ligne le 30 décembre 2018, consulté le 28 septembre 2020. URL : http://journals.openedition.org/ abstractairanica/44095 ; DOI : https://doi.org/10.4000/abstractairanica.44095

Ce document a été généré automatiquement le 28 septembre 2020.

Tous droits réservés 


\title{
Markham J. Geller (ed.). The Archaeology and Material Culture of the Babylonian Talmud
}

\author{
Florence Jullien
}

\section{RÉFÉRENCE}

Markham J. Geller (ed.). The Archaeology and Material Culture of the Babylonian

Talmud. Leiden: Brill, 2015, XII-403 p. (Institute of Jewish Studies. Studies in Judaica 16), ISBN 9789004304888.

Cet intéressant ouvrage collectif est le fruit d'un colloque organisé à l'Institute of Jewish Studies de l'University College de Londres. Il rassemble seize articles traitant de la culture matérielle (vestiges archéologiques), des connaissances techniques et des pratiques magiques des communautés juives à l'époque du Talmud babylonien (TB), c'est-à-dire vers la fin de la période sassanide. L'un d'eux fait ainsi un point utile sur les vestiges archéologiques de la Babylonie sassanide (St J. Simpson, «Land behind Ctesiphon: the Archaeology of Babylonia during the Period of the Babylonian Talmud»). Plusieurs ont pour objet les pratiques cultuelles déviantes des juifs babyloniens : le recours aux amulettes ou aux formules magiques est largement attesté par l'importance des découvertes de bols incantatoires utilisés dans la communauté (S. Shaked, «Since when do Women go to Miqveh? Archaeological and Rabbinic Evidence, Tal Ilan Rabbis in Incantation Bowls»; S. Bhayro, « Divorcing a Demon: Incantation Bowls and BT Gițtin 85b »; N. Vilozny, « Lilith's Hair and Ashmedai's Horns: Incantation Bowl Imagery in the Light of Talmudic Descriptions »). Une volonté d'une insertion socio-culturelle explique par ailleurs les influences extérieures et l'adoption de coutumes exogènes : fréquentation de gymnases en Babylonie comme à Jérusalem (M. J. Geller, D. T. Potts, "The Gymnasium at Babylon and Jerusalem »), de bains rituels (miqveh) pour les femmes comme le montrent des évidences archéologiques mais aussi littéraires rabbiniques (T. Ilan, «Since when do Women go to Miqveh? Archaeological 
and Rabbinic Evidence »), - un univers matériel réinterprété aussi par leurs coreligionnaires romains de Palestine (Y. Eliav, «The Material World of Babylonia as seen from Roman Palestine : Some Preliminary Observations »), mais aussi par les juifs de la Babylonie sassanide eux-mêmes soucieux de se construire une image propre (I. Gafni, "Biblical 'Archaeology' and Babylonian Rabbis: On the Self-Image of Jews in Sasanian Babylonia»). Cette 'culture partagée' dans la Babylonie du VI siècle est perceptible en maints domaines: dans l'utilisation de calendriers où s'interpénètrent des traditions locales, juives et chrétiennes par exemple (S. Stern, « Rabbinic, Christian, and Local Calendars in Late Antique Babylonia: Influence and Shared Culture »); dans les emprunts lexicaux du judéo-araméen babylonien, la langue du TB (Th. Kwasman, "Loanwords in Jewish Babylonian Aramaic: Some Preliminary Observations»); ou encore dans le partage de mêmes fictions narratives par les sources juives, chrétiennes, musulmanes et persanes (R. Kalmin, " 'Manasseh sawed Isaiah with a Saw of Wood:' an Ancient Legend in Jewish, Christian, Muslim and Persian Sources » - cet article avait déjà fait l'objet d'une publication dans R. Kalmin, Migrating Tales: The Talmud's Narratives and Their Historical Context en 2014). D'autres interventions ont pour thème les voyages entre Palestine et Mésopotamie aux périodes hellénistiques et romaines (G. Cohen, "Travel Between Palestine and Mesopotamia during the Hellenistic and Roman Periods: A Preliminary Study») ou encore les activités économiques et les développements commerciaux (M. Ponting, D. Levene, "'Recycling economies, when efficient, are by their nature invisible.' A First Century Jewish Recycling Economy »; Y. Elman, "Shopping in Ctesiphon: A Lesson in Sasanian Commercial Practice »), avec un développement sur le cèdre dans l'Antiquité judaïque (M. Stone, «The Cedar in Jewish Antiquity »). Une analyse concise effectue une comparaison ciblée sur la loi de la propriété dans le TB et dans la législation sassanide (M. Macuch, «Substance and Fruit in the Sasanian Law of Property and the Babylonian Talmud»). Les actes de ce colloque bien conçu se terminent par d'utiles indices. La mise en commun de ces réflexions sur la culture matérielle des communautés juives de Babylonie dans l'Antiquité tardive permet d'en esquisser un tableau particulièrement vivant.

\section{AUTEURS}

\section{FLORENCE JULLIEN}

CNRS, Mondes iranien et indien, Paris 